\title{
Inflammation, obesity and comorbidities: the role of diet
}

\author{
Mónica Bulló ${ }^{1}$, Patricia Casas-Agustench ${ }^{1}$, Pilar Amigó-Correig ${ }^{1}$, Javier Aranceta ${ }^{2}$ and \\ Jordi Salas-Salvadól,* \\ 'Human Nutrition Unit, Hospital Universitari de Sant Joan, Departament de Bioquímica i Biotecnologia, Facultat \\ de Medicina i Ciències de la Salut, Universitat Rovira i Virgili, C/Sant Llorenç, 2143201 Reus, Spain: \\ ${ }^{2}$ Departamento de Medicina Preventiva y Salud Pública, Universidad de Navarra, Navarra, Spain
}

Submitted 22 November 2006: Accepted 11 December 2006

\begin{abstract}
The adipocyte metabolism has been shown to change during the fat enlargement process associated to obesity. Several procoagulant proteins such as plasminogen activator inhibitor type 1, tissue factor or factor VII and also inducible nitric oxide synthase show higher expression in adipose tissue of obese people in comparison to lean. This overexpression could explain at least a part of the atherogenic and cardiovascular risk associated with obesity.

In addition to cytokine secretion, many other features have been observed to be common to adipocyte and monocyte/macrophage lines: for example, phagocytic and microbicidal activities, and possibly a cellular plasticity of adipose precursors.

Overweight and obesity are associated with an increased risk of such metabolic abnormalities as dyslipidemia, hypertension or type 2 diabetes mellitus and cardiovascular diseases, common features of the metabolic syndrome. Initially, insulin resistance or hyperinsulinemia was suggested as the origin of these abnormalities. More recent studies indicate that adipokynes have an important role in obesity-associated metabolic complications, and suggest that chronically elevated local or systemic concentrations of adipokynes contribute to the development of complications associated with obesity and metabolic syndrome.

Considering all the evidence relating to diet and inflammation, the best diet for protecting against the metabolic derangements associated with obesity and metabolic syndrome would be high in fibre-rich cereals, fruit, vegetables, fish, virgin olive oil and nuts; moderate in wine; and low in meat, processed meat foods and trans-fatty acids.
\end{abstract}

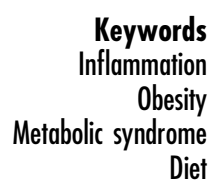

Obesity is considered to be an epidemic of the 21st century. Its prevalence is increasing and its importance to public health is considerable because it is associated with a higher risk of type 2 diabetes, coronary heart disease and certain cancers, and a shorter life expectancy. Although the mechanism underlying the development of obesity and its comorbidities are not well established, it has been recognised that these clusters of disorders are associated to chronic mild inflammation in which the metabolism of fat tissue plays an important role ${ }^{1,2}$.

In recent decades, fat was considered to have a passive role in the development of obesity and was simply stored in the adipocytes. More recently, the adipocyte metabolism has been shown to change during the fat enlargement process associated to obesity. Within these mechanisms, a greater release of free fatty acids (FFA) and glycerol from adipocytes has been described in obese people than in lean individuals, probably promoting insulin resistance and type 2 diabetes through its specific actions that block insulin signal transduction ${ }^{3}$. Several procoagulant proteins such as plasminogen activator inhibitor type 1 , tissue factor or factor VII and also inducible nitric oxide synthase (iNOS) show higher expression in adipose tissue of obese people in comparison to lean people ${ }^{4-7}$. This overexpression could explain at least a part of the atherogenic and cardiovascular risk associated obesity. White adipose tissue is also specially characterised by the production and secretion of more than 50 adipokines, such as leptin, tumour necrosis factor (TNF) or interleukin-6 (IL6) with characterised local and systemic pro-inflammatory effects ${ }^{2,8,9}$. Several of these molecules are over released into the circulation in obese subjects leading to a low grade of chronic systemic inflammation. Recent data indicate that white adipose tissue in obesity is infiltrated by macrophages, where they apparently function to scavenge moribund adipocytes $^{10,11}$. Nevertheless, infiltrated macrophages could be the major source of pro-inflammatory cytokine production 
in obese adipose tissue. Interestingly, weight loss is associated with an improvement in the circulating proinflammatory profile and a reduction in the macrophage infiltration of white adipose tissue ${ }^{12}$.

Although knowledge about the interplay of inflammation and obesity is still being gained, the available evidence indicates that dietary intervention will become an integral part of future approaches to prevent and treat obesity, the metabolic derangements associated with obesity, the metabolic syndrome and ultimately the cardiovascular disease associated with the atherosclerotic processes. For this reason, in this review we analyse the importance of a healthy diet if these metabolic alterations are to be prevented.

\section{Adipose tissue and inflammation}

Since the discovery of leptin in 1994, the perspective on the physiological role of white adipose tissue has dramatically changed and it is now considered to be a major endocrine organ with an important role in the regulation of energy intake and metabolism. Indeed, as explained above, adipose tissue secretes a multiplicity of factors commonly termed adipokines with different protein structures and functions: for example, cytokines or related-proteins (leptin, TNF, IL-6, neurotrophins), chemoattractant proteins (monocyte chemotactic protein-1 (MCP-1)), proteins of the complement system (adipsin), proteins involved in the regulation of blood pressure, vascular haemostasis or angiogenesis (angiotensinogen, plasminogen activator inhibitor-1 (PAI-1), vascular endothelial growth factor (VEGF)), and molecules involved in the glucose and lipid metabolism (adiponectin, resistin, visfatin, cholesteryl ester transfer protein (CETP)). The functional homology between adipocytes and cells from the immune system reinforces the previously observed relationship between adipose tissue and immunity ${ }^{13}$. In addition to cytokine secretion, many other features have been observed to be common to adipocyte and monocyte/macrophage lines: for example, phagocytic and microbicidal activities ${ }^{14}$, and possibly a cellular plasticity of adipose precursors ${ }^{15}$.

The theoretical role of adipose tissue in the development of local or systemic inflammatory status, especially in obesity, could be complicated by its heterogeneity at the cellular level. Mature adipocytes are not more than half of the total cell content of white fat. The remaining cell components contain pre-adipocytes, fibroblast, endothelial cells and macrophages ${ }^{10}$. It is well-documented that during adipose tissue growth, for example in obesity, there is an increase in the size and number of mature adipocytes differentiated from progenitor cells like preadipocytes present in the stroma-vascular fraction. However, this phenomenon seems to be reversible during adult life and the relation between the number of mature adipocytes and preadipocytes can change ${ }^{16}$. Moreover, infiltration of macrophages from peripheral blood has been reported during fat mass expansion in obesity ${ }^{10,17}$. Although the molecular mechanisms responsible for these microphagic infiltrations have not yet been elucidated, some adipokynes such as MCP-1 and leptin can favour the diapedesis of macrophages from circulation to adipose tissue ${ }^{18}$. Macrophages that infiltrate adipose tissue seem to be responsible for almost the total amount of TNF $\alpha$ and a significant part of IL-6 produced by this tissue $^{10}$. Factors secreted by infiltrated macrophages inhibit the differentiation of preadipocytes into mature adipocytes probably because the extracellular matrix is remodelled $^{19}$. So, the real capacity of adipose tissue to produce and release inflammatory proteins may be related to its cellular composition, and depends on the degree of obesity.

\section{Obesity, metabolic syndrome and inflammation}

Overweight and obesity are associated with an increased risk of such metabolic abnormalities as dyslipidemia, hypertension or type 2 diabetes mellitus and cardiovascular diseases - common features of the metabolic syndrome. Initially, insulin resistance or hyperinsulinemia was suggested as the origin of these abnormalities ${ }^{20}$. Nowadays, more recent studies indicate that adipokynes have an important role in obesity-associated metabolic complications, and suggest that chronically elevated local or systemic concentrations of adipokynes contribute to the development of complications associated with obesity and metabolic syndrome.

$\mathrm{TNF} \alpha$ is a potent cytokine that induces the production of IL- 6 , which is the major determinant of the acutephase response ${ }^{16,17}$ and is also produced by adipose tissue. Plasma levels of TNF are persistently elevated in obese or type 2 diabetic patients and among patients at increased risk of recurrent coronary events ${ }^{9,21}$. Its role favoring insulin resistance is mediated by the increase in adipocyte lipolysis ${ }^{22}$ and through its role on insulin receptor substrate-1 phosphorylation and modulating glucose transporter type 4 (GLUT4) activity ${ }^{23}$. Because TNF is the first step in the inflammatory cascade, it is not surprising that plasma levels of IL-6 are high in obese or diabetic subjects ${ }^{8}$. Like TNF, IL-6 concentrations correlate with insulin resistance ${ }^{24,25}$ and increase lipolysis and fat oxidation in humans ${ }^{25}$. Therefore, it is not surprising that elevated levels of IL-6 have been associated with an increased risk of type 2 diabetes $^{26}$ and future myocardial infarction in healthy men ${ }^{27}$.

One of the most important effects of IL-6 is that it controls hepatic C-reative protein (CRP) production, one of the most important inflammatory markers in humans, also positively associated with degree of obesity, fasting glucose and insulin, blood pressure and lipid profile ${ }^{26}$. 
CRP induces the synthesis of other cytokines, cell adhesion molecules such as vascular cell adhesion molecule (VCAM) or intercellular adhesion molecule (ICAM), and tissue factor, and provides a link between inflammation and atherosclerosis ${ }^{28}$. Elevated CRP levels have been described as an independent predictor of risk of type 2 diabetes, myocardial infarction, stroke and peripheral arterial disease even in healthy subjects ${ }^{26,29}$. Other inflammatory markers, such as blood cell count, fibrinogen, ESR, inflammation-associated haemostatic variables and low serum albumin, have also been associated with obesity and its metabolic derangements ${ }^{30}$.

In obesity, the decrease in production and expression of adiponectin, a molecule with an anti-inflammatory action, exacerbates the important role of inflammation in the obese state ${ }^{31,32}$. Plasma adiponectin concentrations are lower in patients who have type 2 diabetes or coronary heart disease than in controls, even when body mass index or age are matched ${ }^{33,34}$. Adiponectin may affect insulin sensitivity because it acts on muscle fatty acid oxidation and hormone-sensitivity lipase ${ }^{2,35}$. The stimulation of nitric oxide production and the reduction in the expression of adhesion molecules in endothelial cells explains the anti-hypertensive and anti-atherogenic properties of adiponectin.

Several clinical studies have demonstrated that it is abdominal fat distribution, not the amount of fat deposition, which is better associated with multiple metabolic risk factors. In fact, epidemiological studies have suggested that abdominal fat distribution is a significant predictor for coronary artery disease independent of body mass index ${ }^{36}$. Quantitative and qualitative changes in serum lipids and lipoproteins such as small dense lowdensity lipoproteins (LDL), hypertriglyceridemia or the hyperinsulinemic state are more closely related to visceral than subcutaneous fat. Furthermore, differences in adipokyne expression and production between visceral and subcutaneous fat depots have also been reported. For example, TNF is significantly overproduced in visceral adipose tissue. Because this cytokine is a strong inhibitor of adiponectin promoter activity ${ }^{37}$, it may explain the negative correlation observed between visceral adiposity and adiponectin levels. It has been speculated that approximately $20 \%$ of all genes in subcutaneous adipose tissue encode secretory proteins, and increase visceral fat by about $30 \%{ }^{38}$. Recently, a visceral-fat-specific adipocytokine, visfatin, was described ${ }^{39}$. Plasma visfatin levels strongly correlated with the amount of visceral adipose tissue estimated by computed tomography ${ }^{39}$. Higher visfatin plasma levels have also been observed in patients with type 2 diabetes mellitus ${ }^{40}$ or in those with rheumatoid arthritis ${ }^{41}$. Although its physiological significance is not fully understood, visfatin mimics the effect of insulin and has a potent activity on adipogenesis.

Although knowledge about the relationship between inflammation and obesity is increasing, whether the inflammatory state is the cause or the consequence of obesity remains to be elucidated. It has been recently proposed that local hypoxia during white adipose tissue mass expansion is the first sign that the production of inflammatory adipokines and related substances is being stimulated. Hypertrophic adipocyte expansion during the development of obesity is associated with low oxygen tension and metabolic adaptation to hypoxia ${ }^{42,43}$. Within the adaptative mechanism, the overexpression of hypoxia-inducible genes such as VEGF, erythropoietin (EPO) or hypoxia-inducible factor (HIF-1) has been described in the adipose tissue of human obese subjects. This overexpression decreases after weight $\operatorname{loss}^{12}$. It has been suggested that these molecules may stimulate the release of inflammatory cytokines and other inflammatory substances ${ }^{44,45}$.

\section{Inflammation and weight loss}

Evidence for a connection between obesity and inflammation has also been found in clinical weight loss studies. Since adipose tissue from obese patients overexpresses adipokynes, it seems reasonable that a reduction in adipose mass after weight loss will restore inflammatory levels because adipose tissue expression and secretion will decrease, and insulin resistance and other cardiovascular risk factors will improve. Several studies of weight loss due to dietary intervention or exercise, report a decrease in circulating levels of several peripheral inflammatory markers ${ }^{46,47}$. Weight loss due to bariatric surgery or fat removal by liposuction is also associated with an improvement in the inflammatory state ${ }^{48}$. However, there are some discrepancies in terms of adipose tissue adipokyne expression after weight loss. While some studies describe a decrease in TNF or IL-6 adipose tissue expression, others have found an increase or no changes ${ }^{49,50}$. As has been previously suggested by our group, these discrepancies may be due to the sign of the energy balance at the moment of the study ${ }^{51}$. While most of the studies describing a decrease in adipokyne expression were made a long time after weight loss, and the weight loss had stabilised, in our study we evaluated subcutaneous adipose tissue adipokyne expression in negative energy balance conditions when lipid metabolism is stimulated. Because several pro-inflammatory cytokines have lipolytic activity, our results were not surprising.

The restoration of inflammatory levels could also be explained by the decrease in the infiltration of macrophage adipose tissue after weight loss ${ }^{10}$ and changes in its distribution $^{12}$. Although the mechanisms responsible for macrophage recruitment in white adipose tissue are unknown, such chemotactic factors as MCP-1 showed decreased expression after weight loss. Tissue and cellular hypoxia is a well-known cause of macrophage 
attraction and retention, particularly in tumours and atherosclerotic plaque ${ }^{52}$. The overexpression of HIF- $1 \alpha$ in morbid obesity and its lower expression after weight loss also indicate that local white adipose tissue hypoxia contributes to macrophage movement, as suggested ${ }^{53}$.

\section{The role of diet in inflammatory modulation}

Inflammation is a normal response to tissue injury or infection. However, several studies suggest that when a source of chronic inflammation exposure persists, a lowgrade inflammation response develops, thus increasing the risk of obesity, insulin resistance, diabetes, metabolic syndrome, cardiovascular disease or cancer ${ }^{26,54-56}$. Dietary habits are probably one of the key determinants of the balance that influences the overall inflammatory process in chronic conditions. Genetic polymorphisms at multiple sites may alter the ability of bioactive food components to influence the overall process by modulating pro- and/or anti-inflammatory mediators. The modulation of this inflammatory response by diet would be fundamental if such metabolic derangements associated with obesity such as insulin resistance, type 2 diabetes, hypertension, atherogenic dyslipidaemia and metabolic syndrome are to be prevented and treated.

The inflammatory process is initiated by the synthesis and secretion of pro-inflammatory cytokines in response to an inflammatory insult (for example, a non-healthy diet). The increased production of cytokines and the subsequent increase in reactive oxygen and nitrogen species are recognised hallmarks of inflammation. This process is regulated by a negative feedback mechanism and is closely followed by the secretion of anti-inflammatory cytokines to reduce the accumulation of reactive species. The cellular anti-oxidant defence system is also activated to limit the development of chronic inflammation in which the risk of metabolic syndrome and subsequently atherosclerosis is much higher than normal.

The binding of pro-inflammatory cytokines to their receptors triggers the mitogen-activated protein kinase (MAPK) pathway that ultimately results in the activation of two redox-sensitive transcription factors: nuclear factor kappa $\mathrm{B}(\mathrm{NF} \kappa \mathrm{B})$ and the $\mathrm{c}-J u n$ part of activating protein-1 (AP-1). These transcription factors activate the expression of a wide variety of genes including cytokines, chemokines, adhesion molecules, and inducible effector enzymes such as iNOS and cycloxygenase-2 (COX-2).

There is evidence to suggest that such dietary components as eicosapentaenoic acid (EPA), docosahexaenoic acid (DHA), butyrate, curcumin, resveratrol, lutein, quercetin and oleuropein can influence the inflammatory process at various sites and thus modulate the balance within the process. For example, the production of IL- 6 or IL- $1 \beta$ in THP- 1 cellules was reduced after incubation with DHA or $\mathrm{ALA}^{57}$. Several phenolic compounds have also been identified as anti-inflammatory compounds; however, phenolic compounds from extra virgin olive oil have been shown to have different anti-inflammatory effects in human whole blood cultures ${ }^{58}$. Likewise, a number of dietary components, including resveratrol in red grapes, butyrate generated through the microbial metabolism of dietary fibre in colon, and curcumin in curry spice, have been reported to suppress the TNF- $\alpha$-induced activation of NF- $\kappa \mathrm{B}$ and COX-2 expression in vitro and in vivo. The mechanisms by which these bioactive components influence inflammation are not known with any certainty, but may involve transport, activation or inactivation processes. Resveratrol has been shown to inhibit the translocation of $\mathrm{NF}-\kappa \mathrm{B}$ from the cytoplasm to the nucleus by modulating the I $\kappa \mathrm{B}$ kinase (IKK) activity in various cell types (for example, myeloid, lymphoid and epithelial cells) ${ }^{59}$.

\section{Cereals, fibre and glycaemic response}

Fasting and postprandial hyperglycaemia are very frequently observed in obesity. They can reduce the availability of nitric oxide ${ }^{60}$, and increase the free radical production, which also activates inflammation by modulating protein kinase $\mathrm{C}$ (PKC) and NF- $\kappa \mathrm{B}$ function ${ }^{61}$. Refined starches and sugars cause a rapid increase in blood glucose and insulin levels, and a subsequent decrease in glycaemia, which leads to hunger and a decrease in fat oxidation. For this mechanism, the intake of foods with a high glycaemic index is associated with hyperglycaemia being a major stimulus for inflammation.

A cross-sectional study performed in 720 diabetic patients between 40 and 75 years old from the Health Profesionals' Follow-up study supports this hypothesis. In this study, subjects with diets low in glycemic load and high in dietary fibre have higher plasma levels of adiponectin, a molecule with anti-inflammatory properties that protects against diabetes and atherosclerosis ${ }^{62}$. Also recently, in two more cross-sectional studies, plasma levels of CRP have been observed to be negatively related to the total fibre intake in 524 healthy adult subjects ${ }^{63}$ and in patients with diabetes, hypertension or obesity from the NHANES study ${ }^{64}$. These associations were maintained when variables were adjusted for other confounding dietary and non-dietary factors. Some interventional studies support the hypothesis that fibre can improve inflammation ${ }^{46}$. In fact, recent epidemiologic studies suggest that a high consumption of dietary fibre or cereals decreases the risk of diabetes or atherosclerosis and is associated with a decrease in weight gain ${ }^{65-67}$.

\section{Fish and omega-3 fatty acids}

One of the most commonly studied dietary compounds is omega-3 ( $\omega 3)$ fatty acids. $\omega 3$ fatty acids (especially EPA 
and DHA) decrease the arachidonic acid content of cell membranes, which results in the synthesis of eicosanoids that have fewer inflammatory properties than those synthesised from omega-6 ( $\omega 6)$ fatty acids. Several studies support the idea that $\omega 3$ may play a major role in modulating inflammation associated with diseases and situations.

Several cross-sectional studies support the idea that $\omega 3$ fatty acids have anti-inflammatory properties. In a sample of individuals from the Nurses' Health Study II and the Health Professionals Follow-up Study, Pischon et al. ${ }^{68}$ observed that a high intake of $\omega 3$ (EPA and DHA) and a low intake of $\omega 6$ (linoleic acid) was associated with lower levels of soluble TNF receptors 1 and 2, indicating a low level of inflammation. This anti-inflammatory effect of EPA and DHA has also been observed in other crosssectional studies performed in healthy individuals from the Nurses' Health Study ${ }^{69}$ and the Attica Study ${ }^{70}$ or in patients with established coronary artery disease ${ }^{71}$. Some interventional studies also support the anti-inflammatory effect of the $\omega 3$ in humans. For example, dietary fish oil has been observed to decrease CRP and IL-6 in postmenopausal women ${ }^{72}$. The anti-inflammatory effects of the $\alpha$-linolenic acid have also been observed in several interventional studies ${ }^{73-75}$.

\section{Trans- and saturated fatty acids}

Some observational and interventional studies in humans suggest that diets rich in trans- or saturated fatty acids are more closely associated with inflammation than vegetarian diets, which usually contain fewer of these compounds. For example, subjects consuming a diet rich in trans-fatty acids showed higher levels of CRP, IL-6, sTNFR2, E-selectin, sICAM-1 and sVCAM-1 than those in the low quintile of trans-fatty acid consumption ${ }^{76}$. In a randomised cross-over study, CRP and IL-6 increased when $9 \%$ of fatty acids were replaced with trans-fatty acid or estearic $\operatorname{acid}^{77}$. However, some studies show that intake of trans-fatty acid has no effect on inflammatory parameters. CRP levels increase with trans-fatty acid substitution in a high fat diet in healthy subjects, whereas $6 \%$ substitution of trans-fatty acids in a standard fat diet (30\% fat) showed no effects on CRP in moderately hypercholesterolemic subjects although TNF and IL-6 levels increased ${ }^{78}$.

\section{Virgin olive oil and nuts}

Other important foods with anti-inflammatory properties are virgin olive oil and nuts. Virgin olive oil is a rich source of MUFA, and retains all the lipophilic components of the olive fruit, especially the phenolic compounds with strong anti-oxidant and anti-inflammatory properties ${ }^{79,80}$.
The administration of olive oil with a high phenolic content has been shown to protect against inflammation $^{81}$. In addition, phenolic compounds derived from extra virgin oil were recently shown to decrease the production of inflammatory mediators in human wholeblood cultures ${ }^{58}$ and to inhibit endothelial adhesion molecule expression in vitro ${ }^{82}$. These processes may at least partly explain why the Mediterranean-type pattern of food intake is thought to protect against atherosclerosis.

Nuts are rich in unsaturated fatty acids ${ }^{83}$ and, besides having favourable fatty acid profiles, they are a good source of bioactive compounds with potential benefits against metabolic syndrome and cardiovascular disease. Nuts are rich in fibre ${ }^{84}$, phenolic compounds and other anti-inflammatory and anti-oxidant molecules ${ }^{85}$. Also, nuts contain sizeable amounts of L-arginine, a precursor of the endogenous vasodilator nitric oxide ${ }^{86,87}$. Walnuts differ from all other nuts in that they have a high $\alpha$ linolenic acid content ${ }^{88,89}$ which also has anti-inflammatory properties. A high consumption of nuts and seeds has recently been shown to be associated with lower concentrations of inflammatory markers in the MESA atherosclerosis study ${ }^{90}$. Also, clinical trials of nut consumption have reported decreases in inflammatory markers ${ }^{75}$ and improvements in the endothelial function ${ }^{91}$. This mechanism has been proposed as a potential explanation for the established cardio-protective effect of frequent nut intake $\mathrm{e}^{92}$.

\section{Fruit and vegetables}

An increase in the consumption of fruit and vegetables has also been advocated for the prevention of strokes and other cardiovascular events ${ }^{93}$. Fruit and vegetables are very rich in anti-oxidants and other anti-inflammatory phytochemicals. Plasma CRP and homocysteine concentrations have been related to frequent fruit and vegetable intake in the Massachusetts Hispanic Elders Cross-sectional Study after adjusting for confounding variables. Moreover, a significant relationship between vitamin $\mathrm{C}$ or $\beta$-carotene and CRP levels has been observed in healthy subjects ${ }^{94}$. Several interventional studies have demonstrated an anti-inflammatory effect of fruit and vegetable or some of their individual compounds ${ }^{95-97}$.

\section{Wine and alcohol}

Both epidemiological and experimental studies have proposed that moderate consumption of red wine can contribute to promote health and prevent disease probably because of their content of resveratrol or other polyphenolic compounds and flavonoids, and their effect 
on the modulation of inflammation. A 4-week consumption of $30 \mathrm{~g} \mathrm{day}^{-1}$ of red wine led to a significant decrease in the serum concentration of CRP, VCAM and ICAM in healthy adult men ${ }^{98}$. Lower levels of circulating CRP have also been observed associated to a moderate consumption of red wine in a cross-sectional study performed on more than 2800 men and women of the PRINCE study ${ }^{99}$ or in subjects from the NHANES III study ${ }^{100}$. Some of the mechanisms that explain the biological activities of resveratrol involving downregulation of the inflammatory response are the inhibition of synthesis and release of pro-inflammatory cytokines, modification of eicosanoid synthesis, inhibition of activated immune cells, or inhibition of iNOS and COX-2 via the inhibitory effects on $\mathrm{NF} \kappa \mathrm{B}$ or the activator protein-1 (AP-1) ${ }^{101}$. The effect on $\mathrm{NF} \kappa \mathrm{B}$ may explain the suppression of the ex vivo production of TNF, IL-1 and IL-6 by mononuclear blood cells observed after the incubation with trans-resveratrol ${ }^{102}$. Flavonoids are another of the bioactive compounds of red wine with anti-oxidant and anti-inflammatory properties. Studies performed in cell cultures show that the expression of endothelial adhesion molecules is inhibited, which leads to a reduction in atherosclerotic lesion formation $^{103}$.

Moderate alcohol intake has also been associated with beneficial effects on markers of inflammation, independently of the bioactive components of grapes ${ }^{104}$. This effect, however, is controversial ${ }^{105}$.

\section{Healthy dietary pattern}

Considering all the evidence relating to diet and inflammation, the best diet for protecting against the metabolic derangements associated with obesity and metabolic syndrome would be high in fibre-rich cereals, fruit, vegetables, fish, virgin olive oil and nuts; moderate in wine; and low in meat, processed meat foods and transfatty acids. In fact, in a cross-sectional study from the Nurse's Health Study I Cohort, a prudent pattern was associated to low levels of some inflammatory and endothelial function markers in comparison to the results from a Western dietary pattern ${ }^{69}$. Furthermore, the traditional Mediterranean-type diet has been associated to a low risk of cardiovascular disease ${ }^{106}$ probably mediated by inflammation related factors ${ }^{107,108}$ although some of the results are controversial ${ }^{109}$. Some unpublished results from our group show lower serum concentrations of inflammatory markers, especially those related to endothelial function, in those subjects who consume more fruit, cereals, olive oil and nuts. However, controlled trials analysing the effects of Mediterranean-type diets on inflammation parameters are required if the cross-talk between diet compounds and the modulation of inflammatory state associated with obesity and metabolic syndrome is to be elucidated.

\section{Acknowledgements}

Sources of funding: Funded in part by the Ministerio de Educación y Ciencia CICYT-AGL2005-0365 and two grants from the Instituto de Salud Carlos III (PI041828 and PI051839), Madrid, Spain.

Conflict of interest declaration: No authors have any conflict of interest.

Authorship responsibilities: All the authors have participated in the redaction of the manuscript.

\section{References}

1 Yudkin JS, Stehouwer CD, Emeis JJ, Coppack SW. Creactive protein in healthy subjects: associations with obesity, insulin resistance, and endothelial dysfunction: a potential role for cytokines originating from adipose tissue? Arteriosclerosis Thrombosis and Vascular Biology 1999; 19(4): 972-8.

2 Bullo M, Garcia-Lorda P, Megias I, Salas-Salvado J. Systemic inflammation, adipose tissue tumor necrosis factor, and leptin expression. Obesity Research 2003; 11(4): 525-31.

3 Horowitz JF, Coppack SW, Paramore D, Cryer PE, Zhao G, Klein S. Effect of short-term fasting on lipid kinetics in lean and obese women. American Journal of Physiology 1999; 276(2 Pt 1): E278-84.

4 Samad F, Yamamoto K, Loskutoff DJ. Distribution and regulation of plasminogen activator inhibitor-1 in murine adipose tissue in vivo. Induction by tumor necrosis factoralpha and lipopolysaccharide. Journal of Clinical Investigation 1996; 97(1): 37-46.

5 Samad F, Pandey M, Loskutoff DJ. Tissue factor gene expression in the adipose tissues of obese mice. Proceedings of the National Academic of Science USA 1998; 95(13): 7591-6.

6 De Pergola G, Pannacciulli N. Coagulation and fibrinolysis abnormalities in obesity. Journal of Endocrinology Investigation 2002; 25(10): 899-904.

7 Perreault M, Marette A. Targeted disruption of inducible nitric oxide synthase protects against obesity-linked insulin resistance in muscle. Nature Medicine 2001; 7(10): 1138-43.

8 Fried SK, Bunkin DA, Greenberg AS. Omental and subcutaneous adipose tissues of obese subjects release interleukin-6: depot difference and regulation by glucocorticoid. Journal of Clinical Endocrinology and Metabolism 1998; 83(3): 847-50.

9 Bullo M, Garcia-Lorda P, Peinado-Onsurbe J, Hernandez M, Del Castillo D, Argiles JM, et al. TNFalpha expression of subcutaneous adipose tissue in obese and morbid obese females: relationship to adipocyte LPL activity and leptin synthesis. International Journal of Obesity and Related Metabolic Disorders 2002; 26(5): 652-8.

10 Weisberg SP, McCann D, Desai M, Rosenbaum M, Leibel RL, Ferrante Jr AW. Obesity is associated with macrophage accumulation in adipose tissue. Journal of Clinical Investigation 2003; 112(12): 1796-808.

11 Cinti S, Mitchell G, Barbatelli G, Murano I, Ceresi E, Faloia E, et al. Adipocyte death defines macrophage localization and function in adipose tissue of obese mice and humans. Journal of Lipid Research 2005; 46(11): 2347-55.

12 Cancello R, Henegar C, Viguerie N, Taleb S, Poitou C, Rouault $\mathrm{C}$, et al. Reduction of macrophage infiltration and chemoattractant gene expression changes in white adipose tissue of morbidly obese subjects after surgeryinduced weight loss. Diabetes 2005; 54(8): 2277-86. 
13 Stallone DD. The influence of obesity and its treatment on the immune system. Nutrition Reviews 1994; 52(2 Pt 1): $37-50$.

14 Cousin B, Munoz O, Andre M, Fontanilles AM, Dani C, Cousin JL, et al. A role for preadipocytes as macrophagelike cells. FASEB Journal 1999; 13(2): 305-12.

15 Charriere G, Cousin B, Arnaud E, Andre M, Bacou F, Penicaud L, et al. Preadipocyte conversion to macrophage. Evidence of plasticity. Journal of Biological Chemistry 2003; 278(11): 9850-5.

16 Zhang B, Berger J, Hu E, Szalkowski D, White-Carrington $\mathrm{S}$, Spiegelman BM, et al. Negative regulation of peroxisome proliferator-activated receptor-gamma gene expression contributes to the antiadipogenic effects of tumor necrosis factor-alpha. Molecular Endocrinology 1996; 10(11): 1457-66.

17 Xu H, Barnes GT, Yang Q, Tan G, Yang D, Chou CJ, et al. Chronic inflammation in fat plays a crucial role in the development of obesity-related insulin resistance. Journal of Clinical Investigation 2003; 112(12): 1821-30.

18 Curat CA, Miranville A, Sengenes C, Diehl M, Tonus C, Busse R, et al. From blood monocytes to adipose tissueresident macrophages: induction of diapedesis by human mature adipocytes. Diabetes 2004; 53(5): 1285-92.

19 Lacasa D, Taleb S, Keophiphath M, Miranville A, Clement K. Macrophage-secreted factors impair human adipogenesis: involvement of proinflammatory state in preadipocytes. Endocrinology 2006; 148(2): 868-77. November 2 [Epub ahead of print].

20 Reaven GM. Banting lecture 1988. Role of insulin resistance in human disease. Diabetes 1988; 37(12): 1595-607.

21 Ridker PM, Rifai N, Pfeffer M, Sacks F, Lepage S, Braunwald E. Elevation of tumor necrosis factor-alpha and increased risk of recurrent coronary events after myocardial infarction. Circulation 2000; 101(18): 2149-53.

22 Souza SC, Palmer HJ, Kang YH, Yamamoto MT, Muliro KV, Paulson KE, et al. TNF-alpha induction of lipolysis is mediated through activation of the extracellular signal related kinase pathway in 3T3-L1 adipocytes. Journal of Cellular Biochemistry 2003; 89(6): 1077-86.

23 Bullo-Bonet M, Garcia-Lorda P, Lopez-Soriano FJ, Argiles $\mathrm{JM}$, Salas-Salvado J. Tumour necrosis factor, a key role in obesity? FEBS Letter 1999; 451(3): 215-19.

24 Kern PA, Ranganathan S, Li C, Wood L, Ranganathan G. Adipose tissue tumor necrosis factor and interleukin- 6 expression in human obesity and insulin resistance. American Journal of Physiology, Endocrinology and Metabolism 2001; 280(5): E745-51.

25 van Hall G, Steensberg A, Sacchetti M, Fischer C, Keller C, Schjerling P, et al. Interleukin-6 stimulates lipolysis and fat oxidation in humans. Journal of Clinical Endocrinology and Metabolism 2003; 88(7): 3005-10.

26 Pradhan AD, Manson JE, Rifai N, Buring JE, Ridker PM. C-reactive protein, interleukin 6 , and risk of developing type 2 diabetes mellitus. Journal of the American Medical Association 2001; 286(3): 327-34.

27 Ridker PM, Rifai N, Pfeffer M, Sacks F, Lepage S, Braunwald E. Elevation of tumor necrosis factor-alpha and increased risk of recurrent coronary events after myocardial infarction. Circulation 2000; 101(18): 2149-53.

28 Gabay C, Kushner I. Acute-phase proteins and other systemic responses to inflammation. New England Journal of Medicine 1999; 340(6): 448-54.

29 Torres JL, Ridker PM. Clinical use of high sensitivity Creactive protein for the prediction of adverse cardiovascular events. Current Opinion in Cardiology 2003; 18(6): $471-8$.

30 Dixon JB, O'Brien PE. Obesity and the white blood cell count: changes with sustained weight loss. Obesity Surgery 2006; 16(3): 251-7.
31 Arita Y, Kihara S, Ouchi N, Takahashi M, Maeda K, Miyagawa $\mathrm{J}$, et al. Paradoxical decrease of an adiposespecific protein, adiponectin, in obesity. Biochemical and Biophysics Research Communication 1999; 257(1): 79-83.

32 Bulló M, Salas-Salvado J, Garcia-Lorda P. Adiponectin expression and adipose tissue lipolytic activity in lean and obese women. Obesity Surgery 2005; 15(3): 382-6.

33 Hotta K, Funahashi T, Arita Y, Takahashi M, Matsuda M, Okamoto Y, et al. Plasma concentrations of a novel, adipose-specific protein, adiponectin, in type 2 diabetic patients. Arteriosclerosis, Thrombosis and Vascular Biology 2000; 20(6): 1595-9.

34 Ouchi N, Kihara S, Funahashi T, Matsuzawa Y, Walsh K. Obesity, adiponectin and vascular inflammatory disease. Current Opinión in Lipidology 2003; 14(6): 561-6.

35 Tomas E, Tsao TS, Saha AK, Murrey HE, Zhang Cc C, Itani SI, et al. Enhanced muscle fat oxidation and glucose transport by ACRP30 globular domain: acetyl-CoA carboxylase inhibition and AMP-activated protein kinase activation. Proceedings of the National Academic of Science USA 2002; 99(25): 16309-13.

36 Larsson B, Svardsudd K, Welin L, Wilhelmsen L, Bjorntorp $\mathrm{P}$, Tibblin G. Abdominal adipose tissue distribution, obesity, and risk of cardiovascular disease and death: 13 year follow up of participants in the study of men born in 1913. British Medical Journal (Clinical Research Ed) 1984; 288(6428): 1401-4.

37 Maeda N, Takahashi M, Funahashi T, Kihara S, Nishizawa H, Kishida K, et al. PPARgamma ligands increase expression and plasma concentrations of adiponectin, an adiposederived protein. Diabetes 2001; 50(9): 2094-9.

38 Matsuzawa Y. The metabolic syndrome and adipocytokines. FEBS Letter 2006; 580(12): 2917-21.

39 Fukuhara A, Matsuda M, Nishizawa M, Segawa K, Tanaka $\mathrm{M}$, Kishimoto $\mathrm{K}$, et al. Visfatin: a protein secreted by visceral fat that mimics the effects of insulin. Science 2005; 307(5708): 426-30.

40 Hammarstedt A, Pihlajamaki J, Rotter Sopasakis V, Gogg S, Jansson PA, Laakso M, et al. Visfatin is an adipokine, but it is not regulated by thiazolidinediones. Journal of Clinical Endocrinology and Metabolism 2006; 91(3): 1181-4.

41 Chen MP, Chung FM, Chang DM, Tsai JC, Huang HF, Shin SJ, et al. Elevated plasma level of visfatin/pre-B cell colony-enhancing factor in patients with type 2 diabetes mellitus. Journal of Clinical Endocrinology and Metabolism 2006; 91(1): 295-9.

42 Fleischmann E, Kurz A, Niedermayr M, Schebesta K, Kimberger O, Sessler DI, et al. Tissue oxygenation in obese and non-obese patients during laparoscopy. Obesity Surgery 2005; 15(6): 813-19.

43 Kabon B, Nagele A, Reddy D, Eagon C, Fleshman JW, Sessler DI, et al. Obesity decreases perioperative tissue oxygenation. Anesthesiology 2004; 100(2): 274-80.

44 Lolmede K, Durand de Saint Front V, Galitzky J, Lafontan M, Bouloumie A. Effects of hypoxia on the expression of proangiogenic factors in differentiated 3T3F442A adipocytes. International Journal of Obesity and Related Metabolic Disorders 2003; 27(10): 1187-95.

45 Segawa K, Fukuhara A, Hosogai N, Morita K, Okuno Y, Tanaka $\mathrm{M}$, et al. Visfatin in adipocytes is upregulated by hypoxia through HIF1alpha-dependent mechanism. Biochemistry and Biophysics Research Communication 2006; 349(3): 875-82.

46 Esposito K, Pontillo A, Di Palo C, Giugliano G, Masella M, Marfella R, et al. Effect of weight loss and lifestyle changes on vascular inflammatory markers in obese women: a randomized trial. Journal of the American Medical Association 2003; 289(14): 1799-804.

47 Troseid M, Lappegard KT, Claudi T, Damas JK, Morkrid L, Brendberg R, et al. Exercise reduces plasma levels of the 
chemokines MCP-1 and IL- 8 in subjects with the metabolic syndrome. European Heart Journal 2004; 25(4): 349-55.

48 Haider DG, Schindler K, Schaller G, Prager G, Wolzt M, Ludvik B. Increased plasma visfatin concentrations in morbidly obese subjects are reduced after gastric banding. Journal of Clinical Endocrinology and Metabolism 2006; 91(4): 1578-81.

49 Bastard JP, Hainque B, Dusserre E, Bruckert E, Robin D, Vallier $\mathrm{P}$, et al. Peroxisome proliferator activated receptorgamma, leptin and tumor necrosis factor-alpha mRNA expression during very low calorie diet in subcutaneous adipose tissue in obese women. Diabetes and Metabolism Research Review 1999; 15(2): 92-8.

50 Viguerie N, Vidal H, Arner P, Holst C, Verdich C, Avizou S, et al. Adipose tissue gene expression in obese subjects during low-fat and high-fat hypocaloric diets. Diabetologia 2005; 48(1): 123-31.

51 Salas-Salvado J, Bullo M, Garcia-Lorda P, Figueredo R, Del Castillo D, Bonada A, et al. Subcutaneous adipose tissue cytokine production is not responsible for the restoration of systemic inflammation markers during weight loss. International Journal of Obesity (London) 2006; 30(12): 1714-20.

52 Murdoch C, Giannoudis A, Lewis CE. Mechanisms regulating the recruitment of macrophages into hypoxic areas of tumors and other ischemic tissues. Blood 2004; 104(8): 2224-34.

53 Trayhurn P, Wood IS. Adipokines: inflammation and the pleiotropic role of white adipose tissue. British Journal of Nutrition 2004; 92(3): 347-55.

54 Ridker PM. High-sensitivity C-reactive protein, inflammation, and cardiovascular risk: from concept to clinical practice to clinical benefit. American Heart Journal 2004; 148(Suppl. 1): S19-26.

55 Danesh J, Whincup P, Walker M, Lennon L, Thomson A, Appleby $\mathrm{P}$, et al. Low grade inflammation and coronary heart disease: prospective study and updated metaanalyses. British Medical Journal 2000; 321(7255): 199-204.

56 Danesh J, Wheeler JG, Hirschfield GM, Eda S, Eiriksdottir G, Rumley A, et al. C-reactive protein and other circulating markers of inflammation in the prediction of coronary heart disease. New England Journal of Medicine 2004; 350(14): 1387-97.

57 Zhao G, Etherton TD, Martin KR, Vanden Heuvel JP, Gillies PJ, West SG, et al. Anti-inflammatory effects of polyunsaturated fatty acids in THP-1 cells. Biochemical Biophysics Research Communication 2005; 336(3): 909-17.

58 Miles EA, Zoubouli P, Calder PC. Differential antiinflammatory effects of phenolic compounds from extra virgin olive oil identified in human whole blood cultures. Nutrition 2005; 21(3): 389-94.

59 Manna SK, Mukhopadhyay A, Aggarwal BB. Resveratrol suppresses TNF-induced activation of nuclear transcription factors NF-kappa B, activator protein-1, and apoptosis: potential role of reactive oxygen intermediates and lipid peroxidation. Journal of Immunology 2000; 164(12): 6509-19.

60 Giugliano D, Marfella R, Coppola L, Verrazzo G, Acampora R, Giunta R, et al. Vascular effects of acute hyperglycemia in humans are reversed by L-arginine. Evidence for reduced availability of nitric oxide during hyperglycemia. Circulation 1997; 95(7): 1783-90.

61 Giugliano D, Ceriello A, Esposito K. The effects of diet on inflammation: emphasis on the metabolic syndrome. Journal of American College of Cardiology 2006; 48(4): 677-85.

62 Qi L, Meigs JB, Liu S, Manson JE, Mantzoros C, Hu FB. Dietary fibers and glycemic load, obesity, and plasma adiponectin levels in women with type 2 diabetes. Diabetes Care 2006; 29(7): 1501-5.
63 Ma Y, Griffith JA, Chasan-Taber L, Olendzki BC, Jackson E, Stanek 3rd EJ, et al. Association between dietary fiber and serum C-reactive protein. American Journal of Clinical Nutrition 2006; 83(4): 760-6.

64 Ajani UA, Ford ES, Mokdad AL. Dietary fiber and Creactive protein findings from Nacional Health Nutrition Examination Survey data. Journal of Nutrition 2004; 134: 1181-5.

65 Liu S, Buring JE, Sesso HD, Rimm EB, Willett WC, Manson JE. A prospective study of dietary fiber intake and risk of cardiovascular disease among women. Journal of American Collage of Cardiology 2002; 39(1): 49-56.

66 Ludwig DS, Pereira MA, Kroenke CH, Hilner JE, Van Horn L, Slattery ML, et al. Dietary fiber, weight gain, and cardiovascular disease risk factors in young adults. Journal of the American Medical Association 1999; 282(16): 1539-46.

67 Pereira MA, O'Reilly E, Augustsson K, Fraser GE, Goldbourt U, Heitmann BL, et al. Dietary fiber and risk of coronary heart disease: a pooled analysis of cohort studies. Archives of Internal Medicine 2004; 164(4): 370-6.

68 Pischon T, Hankinson SE, Hotamisligil GS, Rifai N, Willett WC, Rimm EB. Habitual dietary intake of n-3 and $n-6$ fatty acids in relation to inflammatory markers among US men and women. Circulation 2003; 108(2): 155-60.

69 Lopez-Garcia E, Schulze MB, Manson JE, Meigs JB, Albert $\mathrm{CM}$, Rifai $\mathrm{N}$, et al. Consumption of (n-3) fatty acids is related to plasma biomarkers of inflammation and endothelial activation in women. Journal of Nutrition 2004; 134(7): 1806-11.

70 Zampelas A, Panagiotakos DB, Pitsavos C, Das UN, Chrysohoou C, Skoumas Y, et al. Fish consumption among healthy adults is associated with decreased levels of inflammatory markers related to cardiovascular disease: the ATTICA study. Journal of American College of Cardiology 2005; 46(1): 120-4.

71 Madsen T, Skou HA, Hansen VE, Fog L, Christensen JH, Toft E, et al. C-reactive protein, dietary n-3 fatty acids, and the extent of coronary artery disease. American Journal of Cardiology 2001; 88(10): 1139-42.

72 Ciubotaru I, Lee YS, Wander RC. Dietary fish oil decreases C-reactive protein, interleukin-6, and triacylglycerol to HDL-cholesterol ratio in postmenopausal women on HRT. Journal of Nutrition Biochem 2003; 14(9): 513-21.

73 Rallidis LS, Paschos G, Liakos GK, Velissaridou AH, Anastasiadis G, Zampelas A. Dietary alpha-linolenic acid decreases C-reactive protein, serum amyloid $\mathrm{A}$ and interleukin-6 in dyslipidaemic patients. Atherosclerosis 2003; 167(2): 237-42.

74 Bemelmans WJ, Lefrandt JD, Feskens EJ, van Haelst PL, Broer J, Meyboom-de Jong B, et al. Increased alphalinolenic acid intake lowers C-reactive protein, but has no effect on markers of atherosclerosis. European Journal of Clinical Nutrition 2004; 58(7): 1083-9.

75 Zhao G, Etherton TD, Martin KR, West SG, Gillies PJ, Kris-Etherton PM. Dietary alpha-linolenic acid reduces inflammatory and lipid cardiovascular risk factors in hypercholesterolemic men and women. Journal of Nutrition 2004; 134(11): 2991-7.

76 Lopez-Garcia E, Schulze MB, Meigs JB, Manson JE, Rifai N, Stampfer MJ, et al. Consumption of trans fatty acids is related to plasma biomarkers of inflammation and endothelial dysfunction. Journal of Nutrition 2005; 135(3): 562-6.

77 Baer DJ, Judd JT, Clevidence BA, Tracy RP. Dietary fatty acids affect plasma markers of inflammation in healthy men fed controlled diets: a randomized crossover study. American Journal of Clinical Nutrition 2004; 79(6): 969-73.

78 Lichtenstein AH, Erkkila AT, Lamarche B, Schwab US, Jalbert SM, Ausman LM. Influence of hydrogenated fat and 
butter on CVD risk factors: remnant-like particles, glucose and insulin, blood pressure and C-reactive protein. Atherosclerosis 2003; 171(1): 97-107.

79 Perez-Jimenez F, Alvarez de Cienfuegos G, Badimon L, Barja $\mathrm{G}$, Battino $\mathrm{M}$, Blanco $\mathrm{A}$, et al. International conference on the healthy effect of virgin olive oil. European Journal of Clinical Investigation 2005; 35(7): 421-4.

80 Fito M, Cladellas M, de la Torre R, Marti J, Alcantara M, Pujadas-Bastardes $\mathrm{M}$, et al. Antioxidant effect of virgin olive oil in patients with stable coronary heart disease: a randomized, crossover, controlled, clinical trial. Atherosclerosis 2005; 181(1): 149-58.

81 Martinez-Dominguez E, de la Puerta R, Ruiz-Gutierrez V. Protective effects upon experimental inflammation models of a polyphenol-supplemented virgin olive oil diet. Inflammation Research 2001; 50(2): 102-6.

82 Carluccio MA, Siculella L, Ancora MA, Massaro M, Scoditti E, Storelli C, et al. Olive oil and red wine antioxidant polyphenols inhibit endothelial activation: antiatherogenic properties of mediterranean diet phytochemicals. Arteriosclerosis, Thrombosis and Vascular Biology 2003; 23(4): 622-9.

83 Kris-Etherton PM, Yu-Poth S, Sabate J, Ratcliffe HE, Zhao G, Etherton TD. Nuts and their bioactive constituents: effects on serum lipids and other factors that affect disease risk. American Journal of Clinical Nutrition 1999; 70(Suppl. 3): 504S-11S.

84 Salas-Salvado J, Bullo M, Perez-Heras A, Ros E. Dietary fibre, nuts and cardiovascular diseases. British Journal of Nutrition 2006; 96(Suppl. 2): S45-51.

85 Halvorsen BL, Holte K, Myhrstad MC, Barikmo I, Hvattum E, Remberg SF, et al. A systematic screening of total antioxidants in dietary plants. Journal of Nutrition 2002; 132(3): 461-71.

86 Cooke JP, Tsao P, Singer A, Wang BY, Kosek J, Drexler H. Anti-atherogenic effect of nuts: is the answer NO? Archives of Internal Medicine 1993; 153(7): 896-902.

87 Fitzpatrick DF, Hirschfield SL, Ricci T, Jantzen P, Coffey RG. Endothelium-dependent vasorelaxation caused by various plant extracts. Journal of Cardiovascular Pharmacology 1995; 26(1): 90-5.

88 Hepburn FN, Exler J, Weihrauch JL. Provisional tables on the content of omega-3 fatty acids and other fat components of selected foods. Journal of American Dietetic Association 1986; 86(6): 788-93.

89 Zwarts L, Savage GP, McNeil DL. Fatty acid content of new zealand-grown walnuts (juglans regia L.). International Journal of Food Science Nutrition 1999; 50(3): 189-94.

90 Jiang R, Jacobs Jr DR, Mayer-Davis E, Szklo M, Herrington $\mathrm{D}$, Jenny NS, et al. Nut and seed consumption and inflammatory markers in the multi-ethnic study of atherosclerosis. American Journal of Epidemiology 2006; 163(3): 222-31.

91 Ros E, Nunez I, Perez-Heras A, Serra M, Gilabert R, Casals $\mathrm{E}$, et al. A walnut diet improves endothelial function in hypercholesterolemic subjects: a randomized crossover trial. Circulation 2004; 109(13): 1609-14.

92 Nash SD, Westpfal M. Cardiovascular benefits of nuts. American Journal of Cardiology 2005; 95(8): 963-5.

93 He FJ, Nowson CA, MacGregor GA. Fruit and vegetable consumption and stroke: meta-analysis of cohort studies. Lancet 2006; 367(9507): 320-6.

94 van Herpen-Broekmans WM, Klopping-Ketelaars IA, Bots ML, Kluft C, Princen H, Hendriks HF, et al. Serum carotenoids and vitamins in relation to markers of endothelial function and inflammation. European Journal of Epidemiology 2004; 19(10): 915-21.
95 Watzl B, Kulling SE, Moseneder J, Barth SW, Bub A. A 4-wk intervention with high intake of carotenoid-rich vegetables and fruit reduces plasma C-reactive protein in healthy, nonsmoking men. American Journal of Clinical Nutrition 2005; 82(5): 1052-8.

96 Devaraj S, Jialal I. Alpha tocopherol supplementation decreases serum C-reactive protein and monocyte interleukin-6 levels in normal volunteers and type 2 diabetic patients. Free Radical Biology and Medicine 2000; 29(8): 790-2.

97 Sanchez-Moreno C, Cano MP, de Ancos B, Plaza L, Olmedilla B, Granado F, et al. High-pressurized orange juice consumption affects plasma vitamin $\mathrm{C}$, antioxidative status and inflammatory markers in healthy humans. Journal of Nutrition 2003; 133(7): 2204-9.

98 Estruch R, Sacanella E, Badia E, Antunez E, Nicolas JM, Fernandez-Sola J, et al. Different effects of red wine and gin consumption on inflammatory biomarkers of atherosclerosis: a prospective randomized crossover trial. Effects of wine on inflammatory markers. Atherosclerosis 2004; 175(1): 117-23.

99 Albert MA, Glynn RJ, Ridker PM. Alcohol consumption and plasma concentration of C-reactive protein. Circulation 2003; 107(3): 443-7.

100 Stewart SH, Mainous Jr AG, Gilbert G. Relation between alcohol consumption and C-reactive protein levels in the adult US population. Journal of the American Board of Family Practice 2002; 15(6): 437-42.

101 Rahman I, Biswas SK, Kirkham PA. Regulation of inflammation and redox signaling by dietary polyphenols. Biochemical Pharmacology 2006; 72(11): 1439-52.

102 Marier JF, Chen K, Prince P, Scott G, del Castillo JR, Vachon P. Production of ex vivo lipopolysaccharide-induced tumor necrosis factor-alpha, interleukin-1beta, and interleukin-6 is suppressed by trans-resveratrol in a concentration-dependent manner. Canadian Journal of Veterinary Research 2005; 69(2): 151-4.

103 Lotito SB, Frei B. Dietary flavonoids attenuate TNFalphainduced adhesion molecule expression in human aortic endothelial cells: structure-function relationships and activity after first-pass metabolism. Journal of Biological Chemistry 2006 September 20 [Epub ahead of print].

104 Rimm EB, Stampfer MJ. Wine, beer, and spirits: are they really horses of a different color? Circulation 2002; 105(24): 2806-7.

105 Estruch R, Coca A, Rodicio JL. High blood pressure, alcohol and cardiovascular risk. Journal of Hypertension 2005; 23(1): 226-9.

106 Trichopoulou A, Costacou T, Bamia C, Trichopoulos D. Adherence to a Mediterranean diet and survival in a Greek population. New England Journal of Medicine 2003; 348(26): 2599-608.

107 Esposito K, Marfella R, Ciotola M, Di Palo C, Giugliano F, Giugliano G, et al. Effect of a Mediterranean-style diet on endothelial dysfunction and markers of vascular inflammation in the metabolic syndrome: a randomized trial. Journal of the American Medical Association 2004; 292(12): 1440-6.

108 Estruch R, Martinez-Gonzalez MA, Corella D, Salas-Salvado $\mathrm{J}$, Ruiz-Gutierrez V, Covas MI, et al. Effects of a mediterranean-style diet on cardiovascular risk factors: a randomized trial. Annals of Internal Medicine 2006; 145(1): 1-1.

109 Michalsen A, Lehmann N, Pithan C, Knoblauch NT, Moebus S, Kannenberg F, et al. Mediterranean diet has no effect on markers of inflammation and metabolic risk factors in patients with coronary artery disease. European Journal of Clinical Nutrition 2006; 60(4): 478-85. 